\title{
Rapid estimation of nutritional elements on citrus leaves by near infrared reflectance spectroscopy
}

\author{
Luis Galvez-Sola1 , Francisco García-Sánchez ${ }^{2,3 *}$, Juan G. Pérez-Pérez ${ }^{3,4}$, \\ Vicente Gimeno ${ }^{5}$, Josefa M. Navarro ${ }^{3,4}$, Raul Moral' ${ }^{1}$, Juan J. Martínez-Nicolás ${ }^{1}$ and \\ Manuel Nieves ${ }^{1}$
}

\section{OPEN ACCESS}

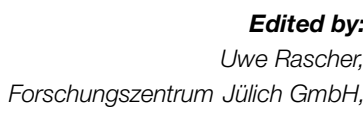

Germany

Reviewed by:

Gerhard Zotz

Carl von Ossietzky Universität Oldenburg, Germany

Zhenzhu Xu,

State Key Laboratory of Vegetation and Environmental Change, Institute

of Botany, Chinese Academy of Sciences, China

*Correspondence

Francisco García-Sánchez, Departamento de Nutrición Vegetal,

Centro de Edafología y Biología

Aplicada del Segura, Consejo

Superior de Investigaciones Científicas, Campus Universitario de Espinardo, Espinardo 30100 ,

Murcia, Spain fgs@cebas.csic.es

Specialty section:

This article was submitted to Functional Plant Ecology,

a section of the journal Frontiers in Plant Science

Received: 28 April 2015 Accepted: 10 July 2015 Published: 23 July 2015

Citation:

Galvez-Sola L, García-Sánchez F,

Pérez-Pérez JG, Gimeno V,

Navarro JM, Moral $R$

Martínez-Nicolás JJ and Nieves $M$

(2015) Rapid estimation of nutritional elements on citrus leaves by near infrared reflectance spectroscopy.

Front. Plant Sci. 6:571. doi: 10.3389/fp/s.2015.00571
${ }^{1}$ Departamento de Producción Vegetal y Microbiología, Miguel Hernández University, Alicante, Spain, ${ }^{2}$ Departamento de Nutrición Vegetal, Centro de Edafología y Biología Aplicada del Segura, Consejo Superior de Investigaciones Científicas, Murcia, Spain, ${ }^{3}$ Unidad Asociada de Fertirriego y Calidad Hortofrutícola (Instituto Murciano de Investigación y Desarrollo Agrario y Alimentario - Centro de Edafología y Biología Aplicada del Segura), Murcia, Spain, ${ }^{4}$ Departamento de Citricultura, Instituto Murciano de Investigación y Desarrollo Agrario y Alimentario, Murcia, Spain, ${ }^{5}$ Departamento de Agronomia, Universidad ISA, Santiago De Los Caballeros, Republica Dominicana

Sufficient nutrient application is one of the most important factors in producing quality citrus fruits. One of the main guides in planning citrus fertilizer programs is by directly monitoring the plant nutrient content. However, this requires analysis of a large number of leaf samples using expensive and time-consuming chemical techniques. Over the last 5 years, it has been demonstrated that it is possible to quantitatively estimate certain nutritional elements in citrus leaves by using the spectral reflectance values, obtained by using near infrared reflectance spectroscopy (NIRS). This technique is rapid, non-destructive, cost-effective and environmentally friendly. Therefore, the estimation of macro and micronutrients in citrus leaves by this method would be beneficial in identifying the mineral status of the trees. However, to be used effectively NIRS must be evaluated against the standard techniques across different cultivars. In this study, NIRS spectral analysis, and subsequent nutrient estimations for $\mathrm{N}, \mathrm{K}, \mathrm{Ca}, \mathrm{Mg}, \mathrm{B}, \mathrm{Fe}$, $\mathrm{Cu}, \mathrm{Mn}$, and $\mathrm{Zn}$ concentration, were performed using 217 leaf samples from different citrus trees species. Partial least square regression and different pre-processing signal treatments were used to generate the best estimation against the current best practice techniques. It was verified a high proficiency in the estimation of $\mathrm{N}(\mathrm{Rv}=0.99)$ and $\mathrm{Ca}$ $(\mathrm{Rv}=0.98)$ as well as achieving acceptable estimation for $\mathrm{K}, \mathrm{Mg}$, Fe, and $\mathrm{Zn}$. However, no successful calibrations were obtained for the estimation of $\mathrm{B}, \mathrm{Cu}$, and $\mathrm{Mn}$.

Keywords: calibration, macronutrients, micronutrients, NIRS, nitrogen, nutritional status

\section{Introduction}

Spain is the largest exporter of fresh fruit in Europe, with more than $50 \%$ of production being commercialized abroad. Citrus is one of most important crops in Spain, with 330,000 hectares currently dedicated to its production along the Mediterranean coast, producing 6.3 million tons of fruit annually. Sweet orange is the most common crop representing $48 \%$ of production, with mandarins and lemons accounting for $35 \%$ and $16 \%$ of production respectively. Like other fruit trees, citrus cultivation requires the right balance of nitrogen, potassium, phosphorous, and trace elements like manganese, boron, copper, and magnesium for vigorous growth and maximum 


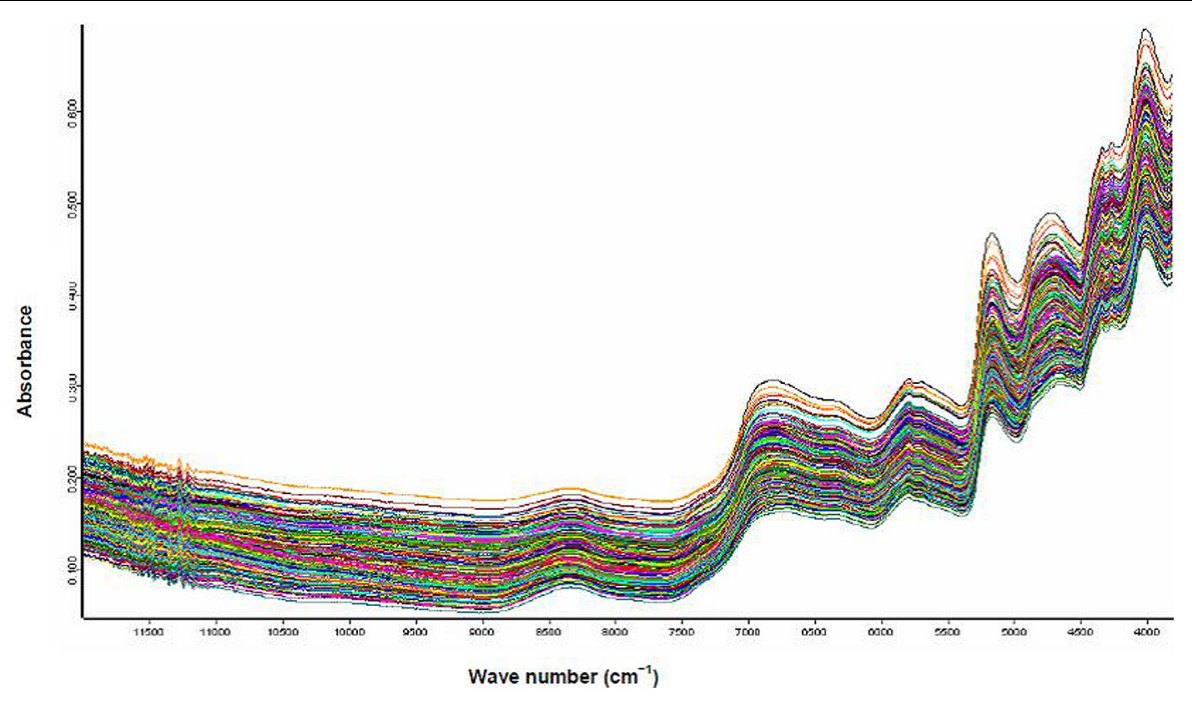

FIGURE 1 | Typical log (1/R) spectra for dry ground citrus leaves samples.

fruit production. Conventionally, leaf analysis has provided a guide for fertilizer applications, according to the sufficiency range (SR), a method based on constructing independent nutrient indices, and including only one nutrient in each index (Walsh, 1973; Jones et al., 1991). A second method is based on dependent nutrient indices, in which each index includes two or more nutrients. Diagnosis and Recommendation Integrated System (DRIS) is the principal example of this approach (Beaufils, 1973).A good fertilization program must pay attention to how the plant mineral status changes through the phenological stages; adapting fertilizer application to meet the requirements of the trees during each stage. Monitoring the effect of plant nutrition on fruit development can require a number of complex chemical analyses in the laboratory, with some experiments needing to run over several years in order to draw the relevant conclusions. This often results in a large number of samples that must be analyzed; which is very time-consuming work, leading to high economic costs and, obviously, have a negative environmental impact owing to the production of noxious chemicals during

TABLE 1 | Range and mean values of the studied elements in the 217 citrus leaves samples, expressed on dry matter basis.

\begin{tabular}{|c|c|c|c|}
\hline Elements & Range & Mean & $\mathbf{S D}^{\mathrm{a}}$ \\
\hline$N\left(g_{100} g^{-1}\right)$ & $1.07-3.86$ & 2.48 & 0.67 \\
\hline$K\left(g_{100} g^{-1}\right)$ & $0.42-1.92$ & 1.13 & 0.35 \\
\hline $\mathrm{Ca}\left(\mathrm{g} 100 \mathrm{~g}^{-1}\right)$ & $0.89-6.77$ & 3.54 & 1.59 \\
\hline $\operatorname{Mg}\left(g 100 g^{-1}\right)$ & $0.14-0.80$ & 0.33 & 0.13 \\
\hline $\mathrm{B}\left(\mathrm{mg} \mathrm{kg}^{-1}\right)$ & $24.22-509.93$ & 110.19 & 84.84 \\
\hline $\mathrm{Fe}\left(\mathrm{mg} \mathrm{kg}^{-1}\right)$ & $39.54-636.75$ & 121.51 & 96.01 \\
\hline $\mathrm{Cu}\left(\mathrm{mg} \mathrm{kg}^{-1}\right)$ & $0.83-11.24$ & 4.59 & 1.52 \\
\hline $\mathrm{Mn}\left(\mathrm{mg} \mathrm{kg}^{-1}\right)$ & $18.69-70.48$ & 38.54 & 9.68 \\
\hline $\mathrm{Zn}\left(\mathrm{mg} \mathrm{kg}^{-1}\right)$ & $9.01-43.92$ & 19.27 & 8.04 \\
\hline
\end{tabular}

aSD, standard deviation. the analysis techniques. Therefore, the development of a fast, environmentally friendly and cheaper method of analysis would be highly desirable.

Near infrared reflectance spectroscopy (NIRS) has the potential to be a useful tool in the quick analysis of numerous samples collected from long term experiments. The main benefits of using this technique are that - after calibration for the element of interest - it is possible to obtain an accurate quantitative estimation for the element in about a minute, without the use of chemical reagents and therefore, without producing pollutants. Additionally, this technique is less expensive than the traditional chemical based techniques and does not require a laborious preparation of samples before analysis.

Near infrared reflectance spectroscopy is based on the absorption of energy by various bonds, such as $\mathrm{C}-\mathrm{H}, \mathrm{C}-\mathrm{C}$, $\mathrm{C}=\mathrm{C}, \mathrm{C}-\mathrm{N}$, and $\mathrm{O}-\mathrm{H}$, which are characteristic of organic matter (Ludwig and Khanna, 2001), in the near infrared spectral range $(700-2,500 \mathrm{~nm})$. In addition, the mineral composition of an organic matrix can be estimated by NIRS owing to the association between minerals and organic functional groups or the organic matrix itself (Huang et al., 2008). So, samples with different organic composition will have a different nearinfrared spectrum. However, in order to accurately estimate the concentration of certain elements in a sample using NIRS, the spectral analysis must first be calibrated against the absorption of known-concentration samples for the element of interest. Besides, the spectrum used in the calibration step must be similar, regarding the organic composition, between them.

There are numerous studies that demonstrate the capability of the NIRS technique concerning the estimation of different elements in plant species for a variety of different purposes. For example, NIRS technology has been successfully used to predict the nutritional quality of forage samples (Alomar et al., 2003), the mineral concentration in alfalfa (Halgerson et al., 
TABLE 2 | Leaf macro and micro-nutrient concentration in the seven citrus plant species.

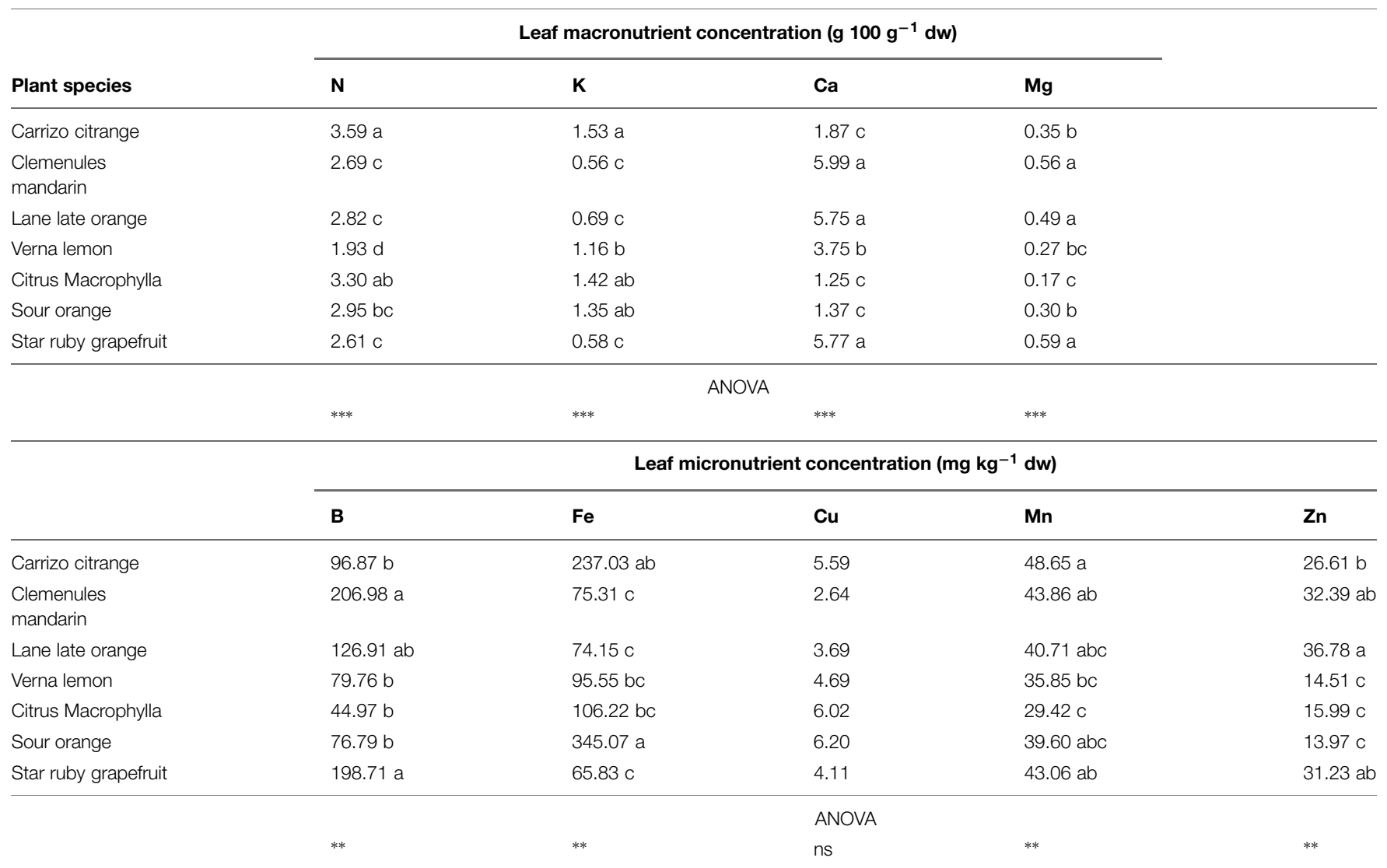

Inside of each column, means $(n=4)$ with the same letter are not significantly different from each other (Duncan test $p>0.05)$. ns indicate non-significant effects; *, ** and ${ }^{* * *}$ indicates significant differences at $p<0.05,0.01$, and 0.001 , respectively.

2004), the quantification of nitrogen concentration in perennial ryegrass and red fescue (Gislum et al., 2004), and for the quality assessment of tomato landraces (García-Martínez et al., 2012). Additionally, there are studies that have demonstrated the usefulness and accuracy of the NIRS in isolation, or in combination with the visible spectroscopy (Vis/NIRS), as a predictive tool for the analysis of citrus products. Examples of this include the analysis of acidity, soluble solids and firmness in mandarins (Hernández Gómez et al., 2006), the measurement of the soluble solids content in oranges (Cayuela, 2008) and citrus fruits before harvest (Zude et al., 2008) and in the classification and analysis of citrus oils (Steuer et al., 2001).

Some works on the analysis of citrus leaf can be found, showing that through the combination Vis/NIRS, it is possible to obtain quantitative estimations of several elements in orange tree leaves (Min et al., 2008; Menesatti et al., 2010). However, there is an absence of studies on the use of the NIRS on leaves across different citrus species. The broad scale applicability of this technique for the quantitative estimation of macro and micronutrients must be demonstrated before it can be considered as a viable alternative to laboratory based techniques. Therefore, the aim of this study was to explore the predictive ability of the NIRS in the evaluation of several elements in citrus leaves of different species.

\section{Materials and Methods}

\section{Citrus Leaves Samples}

A total of 217 leaf samples from different species were used in this research, including 112 of 'Verna' lemon (Citrus limon Burm. F.), 21 'Carrizo' citrange (Citrus sinensis $\times$ Poncirus trifoliata), 21 sour orange (C. aurantium L.), 21 C. macrophylla (C. macrophylla Wester), 15 'Clemenules' mandarin (C. reticulata Blanco), 15 'Lane late' navel orange (C. sinensis L. Osb.) and 12 'Star Ruby' grapefruit (C. paradise Macf.). The six species studied in this experiment were collected from the citrus collection available from the CEBAS-CSIC experimental farm 'Trescaminos' in Santomera (Murcia, Spain) and IMIDA experimental orchard in Torrepacheco (Murcia, Spain).

\section{Analytical Methods}

The leaves were briefly rinsed with deionised water, ovendried at $60^{\circ} \mathrm{C}$ for at least $48 \mathrm{~h}$, and ground to a fine powder. Scanning a ground sample by NIRS can improve the homogeneity of the sample and obtaining repetitive spectra. The mineral concentrations were determined by inductively coupled plasma emission optical spectrometry (Iris Intrepid II, Thermo Electron Corporation, Franklin, MA, USA) in a $0.1 \mathrm{~g}$ sample 
after an acid digestion in $\mathrm{HNO}_{3}: \mathrm{H}_{2} \mathrm{O}_{2}$ (5:3 by volume) in a microwave that reached $190^{\circ} \mathrm{C}$ in $20 \mathrm{~min}$ and held at this temperature for $2 \mathrm{~h}$ (CEM Mars Xpress, Matthews, NC, USA). The nitrogen concentration was determined using a ThermoFinnigan 1112 EA elemental analyser (Thermo-Finnigan, Milan, Italy).

\section{NIRS Analysis}

Near infrared reflectance spectroscopy analysis was performed using a FT-NIR spectrometer (MPA, Bruker Optik GmbH, Germany) in the wave range $12000-3800 \mathrm{~cm}-1(830-2600 \mathrm{~nm})$ with steps of $8 \mathrm{~cm}-1$. Each ground sample was placed in a rotating glass plate of $12 \mathrm{~cm}$ in diameter (similar to the Petri dishes), scanned three times using Opus software (version 6, ${ }^{\circ}$ Bruker Optik), recording absorbance, as $\log 1 / \mathrm{R}$, where $\mathrm{R}$ is reflectance, for a total of 64 scans per sample. The three spectra of each sample were averaged. Due to the rotation of the plate, it was possible to take signal data from different points of the sample. The glass plate must be fully covered with the ground sample. The resulting layer should be at least half a cm thick. Normally, 20-25 g of sample are enough.

Figure 1 shows the NIRS spectra of the citrus leaves samples.

The set of samples mentioned in Section "Citrus Leaves Samples" was divided into two parts: one of 175 samples used for the calibration step (calibration set) and the remaining 42 samples ( $\sim 20 \%$ of the total set) used for the external validation step (validation set). Within the validation set, samples were selected to keep as much similarity from original sample as possible, however, the resultant proportions of the seven citrus varieties varied. The validation set included the following samples: 20 'Verna' lemon, 4 'Carrizo' citrange, 4 sour orange, 3 Citrus macrophylla, 4 'Clemenules' mandarin, 4 'Lane late' navel orange and 3 'Star Ruby' grapefruit. The sample set was split to create the validation set not used in the calibration, to allow for faster processing without the internal validation (cross validation) required when dealing with a large number of samples.
Pre-treatment of spectral data was important to fully or partly eliminate the systematic errors that could be caused by various factors (Galvez-Sola et al., 2010). The following methods were applied: vector normalisation (VN), minimum-maximum normalisation (MMN), multiplicative scatter correction (MSC), first derivative (FD), second derivative (SED), straight line subtraction (SLS) and linear offset subtraction (LOS). A brief explanation of these pre-processing methods can be found in Galvez-Sola et al. (2013). Partial least square regression (PLSR) was used throughout the calibration process, to ensure a good correlation between the spectral data and the concentration values, while different spectra pre-processing methods were tested.

No general recommendation can be given whether the data set should be pre-processed or which method would be best suited. Therefore, the optimal data pre-processing method can only be found empirically by applying several methods in isolation or as a combination to the spectral data, and comparing the results.

To evaluate the estimation, several statistical parameters were performed:

- $R_{\mathrm{c}}$ : coefficient of determination for calibration.

- RMSEE: root mean square error of estimation (calibration step).

- RPD: calculated as the standard deviation divided by the standard error of prediction. (The higher this value, the better)

- F: number of factors or principal components.

- $R_{\mathrm{v}}$ : coefficient of determination for validation.

- RMSEP: root mean square error of prediction (validation step).

- Bias: is the difference between the mean real value and the mean estimated value for the validation set samples (validation step).

Malley et al. (2004) suggest a guideline scale for describing the performance of calibrations for environmental samples: Excellent $R_{\mathrm{V}}>0.95, \mathrm{RPD}>4$; Successful, $R_{\mathrm{V}}=0.9-$ 0.95, RPD 3-4; Moderately Successful, $R_{\mathrm{v}}=0.8-0.9$, RPD

TABLE 3 | Near infrared reflectance spectroscopy calibration and validation results for all studied elements.

\begin{tabular}{|c|c|c|c|c|c|c|c|c|c|c|}
\hline \multirow[t]{2}{*}{ Elements } & \multicolumn{3}{|c|}{ Calibration $^{a}$} & \multicolumn{4}{|c|}{ Validation $^{\mathbf{b}}$} & \multirow[t]{2}{*}{ Factors } & \multirow[t]{2}{*}{ Spectrum region $\left(\mathrm{cm}^{-1}\right)$} & \multirow[t]{2}{*}{ Preprocessing $^{c}$} \\
\hline & $\mathbf{R}_{\mathbf{C}}$ & RMSEE & RPD & $\mathbf{R}_{\mathbf{v}}$ & RMSEP & RPD & Bias & & & \\
\hline$N\left(g 100 g^{-1}\right)$ & 0.98 & 0.09 & 7.89 & 0.99 & 0.06 & 10.9 & 0.0004 & 11 & $6102-4598$ & MMN \\
\hline $\mathrm{K}\left(\mathrm{g} 100 \mathrm{~g}^{-1}\right)$ & 0.94 & 0.09 & 3.95 & 0.88 & 0.12 & 2.86 & 0.0063 & 17 & $7502-4598$ & $\mathrm{FD}+\mathrm{VN}$ \\
\hline $\mathrm{Ca}\left(\mathrm{g} 100 \mathrm{~g}^{-1}\right)$ & 0.98 & 0.25 & 6.39 & 0.98 & 0.25 & 6.94 & 0.0627 & 13 & $7502-4598$ & FD \\
\hline $\operatorname{Mg}\left(g 100 g^{-1}\right)$ & 0.84 & 0.05 & 2.52 & 0.89 & 0.05 & 2.97 & -0.0007 & 8 & $7502-4248$ & MMN \\
\hline $\mathrm{B}\left(\mathrm{mg} \mathrm{kg}^{-1}\right)$ & 0.56 & 59.00 & 1.51 & 0.47 & 53.20 & 1.38 & 0.0521 & 6 & $11996-7498$ & MSC \\
\hline $\mathrm{Fe}\left(\mathrm{mg} \mathrm{kg}^{-1}\right)$ & 0.77 & 44.00 & 2.1 & 0.76 & 60.40 & 2.04 & -3.23 & 15 & $7502-5446$ & MMN \\
\hline $\mathrm{Cu}\left(\mathrm{mg} \mathrm{kg}^{-1}\right)$ & 0.22 & 1.29 & 1.13 & 0.36 & 1.47 & 1.22 & 0.12 & 4 & $5450-4248$ & MMN \\
\hline $\mathrm{Mn}\left(\mathrm{mg} \mathrm{kg}^{-1}\right)$ & 0.77 & 4.99 & 2.08 & 0.53 & 5.55 & 1.46 & -0.394 & 12 & 11996-6098 & - \\
\hline $\mathrm{Zn}\left(\mathrm{mg} \mathrm{kg}^{-1}\right)$ & 0.84 & 3.23 & 2.49 & 0.88 & 3.34 & 2.84 & 0.0683 & 17 & $7502-5446$ & VN \\
\hline
\end{tabular}

${ }^{\mathrm{a}} R_{\mathrm{c}}$, coefficient of determination for calibration; RMSEE, root mean square error of estimation; RPD, calculated as the SD divided by the SE of prediction.

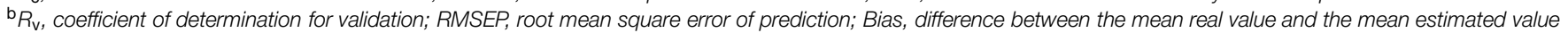
for the validation set samples.

cPreprocessing: VN, vector normalization; MSC, multiplicative scatter correction; FD, first derivative; MMN, minimun-maximun normalization; -, no treatment. 
2.25-3; and Moderately Useful, $R_{\mathrm{V}}=0.7-0.8$, RPD 1.75-2.25. This guideline was used to evaluate the calibrations in this experiment.

\section{Nutritional Diagnostic Indices}

Leaf nutrient analysis from 112 samples 'Verna' lemon plants, mentioned above, were interpreted according to DRIS (Beaufils, 1973). They only provided a basis for comparing the sufficiency of each element relative to other elements, with a high-yield population providing the standard for comparison. For the DRIS index, the mean nutrient ratios used were selected from each pair of inversely related ratios ( $\mathrm{P}: \mathrm{K}, \mathrm{K}: \mathrm{P}$ ) showing the lowest SD. Reference DRIS norms for Verna lemon leaves were used to calculate DRIS index (Cerdá et al., 1995). These DRIS index were used to evaluate the influence of both analytical methods and NIRS estimation on that.

\section{Results and Discussion}

Table 1 shows the mean values, concentration ranges and standard deviation for each element identified from the analytical characterisation of the citrus leaves by classical techniques. This data was used as the 'true' element concentration which was used to evaluate the accuracy of the model estimations from the spectral data. The model was considered to be optimized when the estimated value for the element of interest lay between the same range values.

Table 2 shows the leaf macro and micro-nutrients concentration for the seven plant species used in this experiment. In all nutrients analyzed it was observed significant differences among species, except for leaf $\mathrm{Cu}$ concentration. In addition, Table 1 also show that leaf mineral concentrations ranged in wide intervals. Therefore, these data reflected that using these seven trees species we had a wide range of leaf mineral concentrations. It is important for determining if NIR is a useful technique to predict nutritional status of crops with different requirements.

The $\mathrm{N}$ estimation model was the best predictive model obtained in this study, with very good results in both the calibration and validation processes. The errors in estimation were very low and the coefficient of determination for the validation step was 0.99 (Table 3 ). In addition, the high RPD obtained supported the results and confirmed the high accuracy of this calibration, giving it a ranking of 'Excellent' in the performance scale (Malley et al., 2004). Figure 2 shows the calibration plot for this element.

Satisfactory results were also obtained for the K calibration. In this case, $R_{\mathrm{v}}$ was smaller than that of the $\mathrm{N}$ model, but still good enough for carrying out a prediction for this macronutrient with low errors of estimation. The coefficient of determination in the calibration process was higher than for the validation: 0.94 and 0.88 respectively. Given this situation, it would be desirable to increase the number of samples of the data set and recalculate the model in order to obtain comparable results for both steps (Malley et al., 2004). However, these results still achieve a performance score of 'Moderately Successful.'
The results obtained for $\mathrm{Ca}$ estimation showed that NIRS spectra can again be used as a good predictive model, with very good results in both the calibration and validation processes. $R_{\mathrm{c}}$ and $R_{\mathrm{v}}$ coefficients were 0.98 and the RPD obtained for both steps were high (Table 3 ), supporting the use of NIRS as a great prediction model for this element (Figure 2) with a performance score of 'Excellent.'

The results obtained for $\mathrm{Mg}$ were also promising achieving a performance score of both coefficients $R_{\mathrm{c}}$ and $R_{\mathrm{v}}$ and the RPD were somewhat lower (compared with the Ca model), but the resulting model did not have a high root mean square errors of estimation, as can be seen in Table 3 and in Figure 2. Therefore, the evidence is sufficient to support the use of NIRS as a predictor for this element. These findings support those of Menesatti et al. (2010) which also reported good calibrations for some elements, including $\mathrm{N}$, $\mathrm{K}$, $\mathrm{Ca}$, and $\mathrm{Mg}$, but using Vis-NIR spectroscopy on orange leaves.

In contrast, the estimations for $\mathrm{B}$ and $\mathrm{Cu}$ content were not adequate. In these cases the NIRS estimation method could not generate accurate values for the element concentration, with all statistical parameters far below what would be considered as acceptable for use in the field (Table 3).

The results for Fe estimation were near the limit of what would be considered acceptable. The coefficient $R_{\mathrm{v}}$ was 0.76 and the RPD slightly higher than 2 (Table 3).

Therefore, estimating this element by NIRS would require the acceptance of a prediction error, and this error would increase as the iron concentration of the unknown sample increased (Figure 3). The range of $\mathrm{Fe}$ concentrations within the set of samples was varied (Table 1) and skewed, with $90.3 \%$ of the samples having a value less than $200 \mathrm{mg} \mathrm{kg}^{-1}$, and with few samples exceeding this value. This could adversely affect the generation of the estimation model resulting in the lower coefficients observed.

Interestingly, in the case of Mn estimation, the calibration set results were acceptable, but the validation results did not support the calibration statistics. This indicated it would be beneficial to use more samples to generate another model, in order to achieve a better predictive result, where the calibration and validation sets were analogous.

Finally, Zn content was also a good candidate for estimation by NIRS, achieving a performance score of 'Moderately Successful.' The predictive model resulted in a coefficient of determination validation of 0.88 and $\mathrm{RPD}=2.84$ supporting the accuracy of the estimation.

The good calibration results for most of the studied elements support the evidence that NIRS can be used to accurately estimate the nutrient concentration of some elements in citrus leaves; and additionally, that this technique is applicable across citrus species. The spectra results between species were very similar, with the spectral differences observed not interfering with obtaining good calibrations for the elements of interest.

Furthermore, the number of factors (or principal components) was adequate within all calibrations. He et al. (2007), state that for all calibrations, the number of factors 

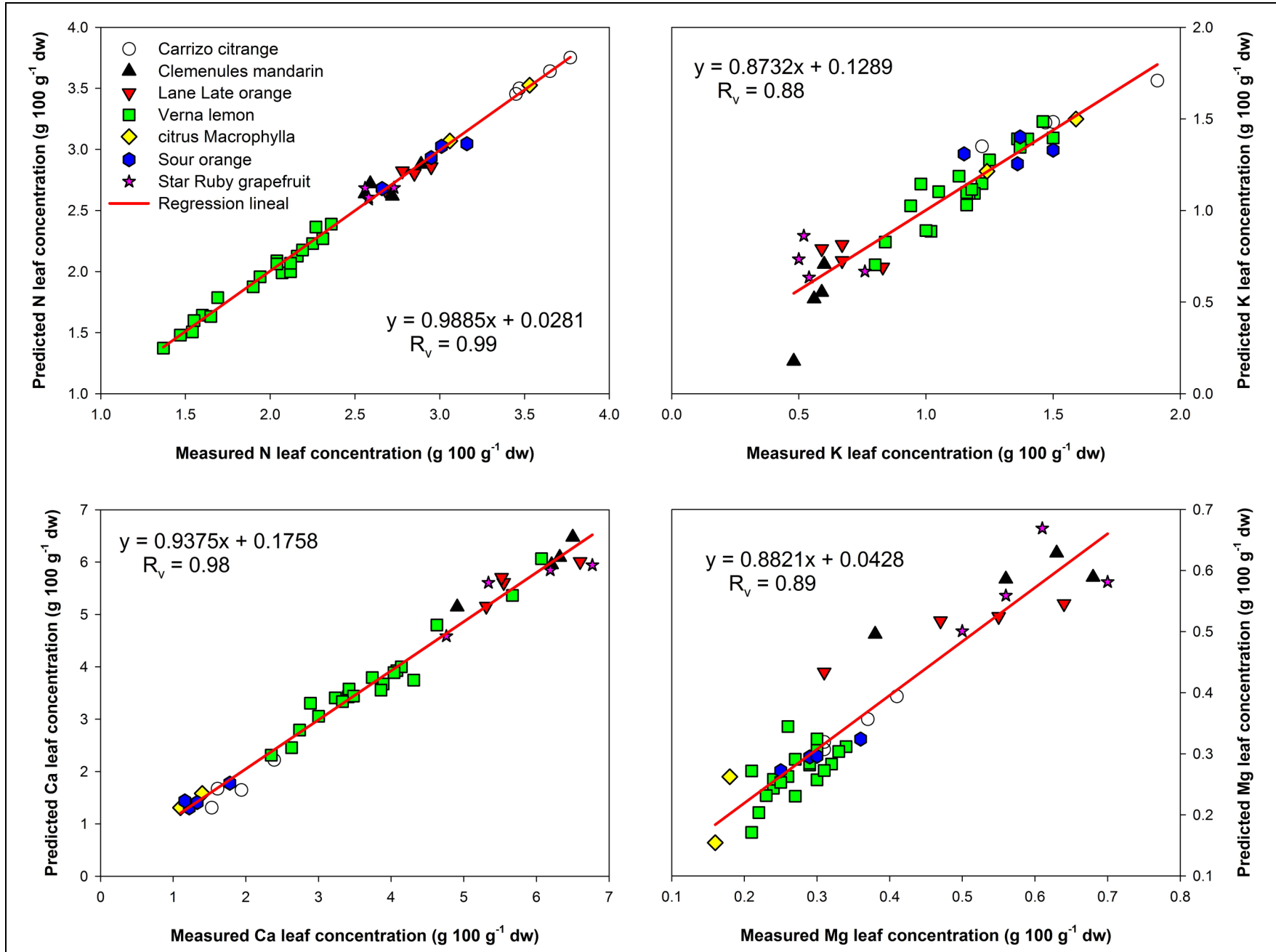

FIGURE 2 | Near infrared reflectance spectroscopy validation plots between predicted and measured values for N, K, Ca, and Mg.

must be not higher than $1 / 10$ the number of samples used in the calibration step. Thus, in this study, the ideal number of factors was 17 or less and this value was not exceeded in any case.

The spectral regions (shown in Table 3) highlight the areas where the spectral information was collected for each element calibration. Interestingly this region usually varied depending on the pre-processing method used. This suggests that further development of the pre-possessing methodology could yield improvements in the estimation accuracy for those elements that scored badly in the performance scale by targeting different areas of the spectra.

Leaf nutrient concentration varied from deficiency level to excess. DRIS index approach provides a basis for determining which element, if any, is likely to limit yield. Because each DRIS index measures deviations from a specific norm, all values in one foliar sample must add up to zero (within a round off error of plus or minus one). The analytical method did not affect the accuracy of the DRIS index since those add up to zero in each sample for both analytical methods (classical techniques and NIRS estimation). The average differences between the DRIS index from both analytical methods for $\mathrm{N}, \mathrm{K}, \mathrm{Ca}$, and $\mathrm{Mg}$ were 3, 3, 5, and 11, respectively. The differences between DRIS index compared to results of calibration show similar consistencies. Researchers have used an in-balance range as wide as -15 to +15 (Kelling and Schulte, 1986). A DRIS index less than -25 indicates a likely deficiency. Values greater than +100 may be an indication of possible nutrient excess. SR and DRIS approach identified nutrient excess and deficiencies in the same foliar samples. These differences between both analytical methods were similar to that observed between nutritional diagnostic indices, like DRIS and Plant Analysis with Standardized Scores, PASS (Baldock and Schulte, 1996).

In summary, according to the suggested guideline described in Section "NIRS Analysis," the calibrations for $\mathrm{N}$ and $\mathrm{Ca}$ were 'Excellent', those for $\mathrm{K}, \mathrm{Mg}$, and $\mathrm{Zn}$ were 'Moderately Successful' and the calibration for $\mathrm{Fe}$ was 'Moderately Useful,' with the NIRS calibrations for $\mathrm{B}, \mathrm{Cu}$, and $\mathrm{Mn}$ being inadequate. 

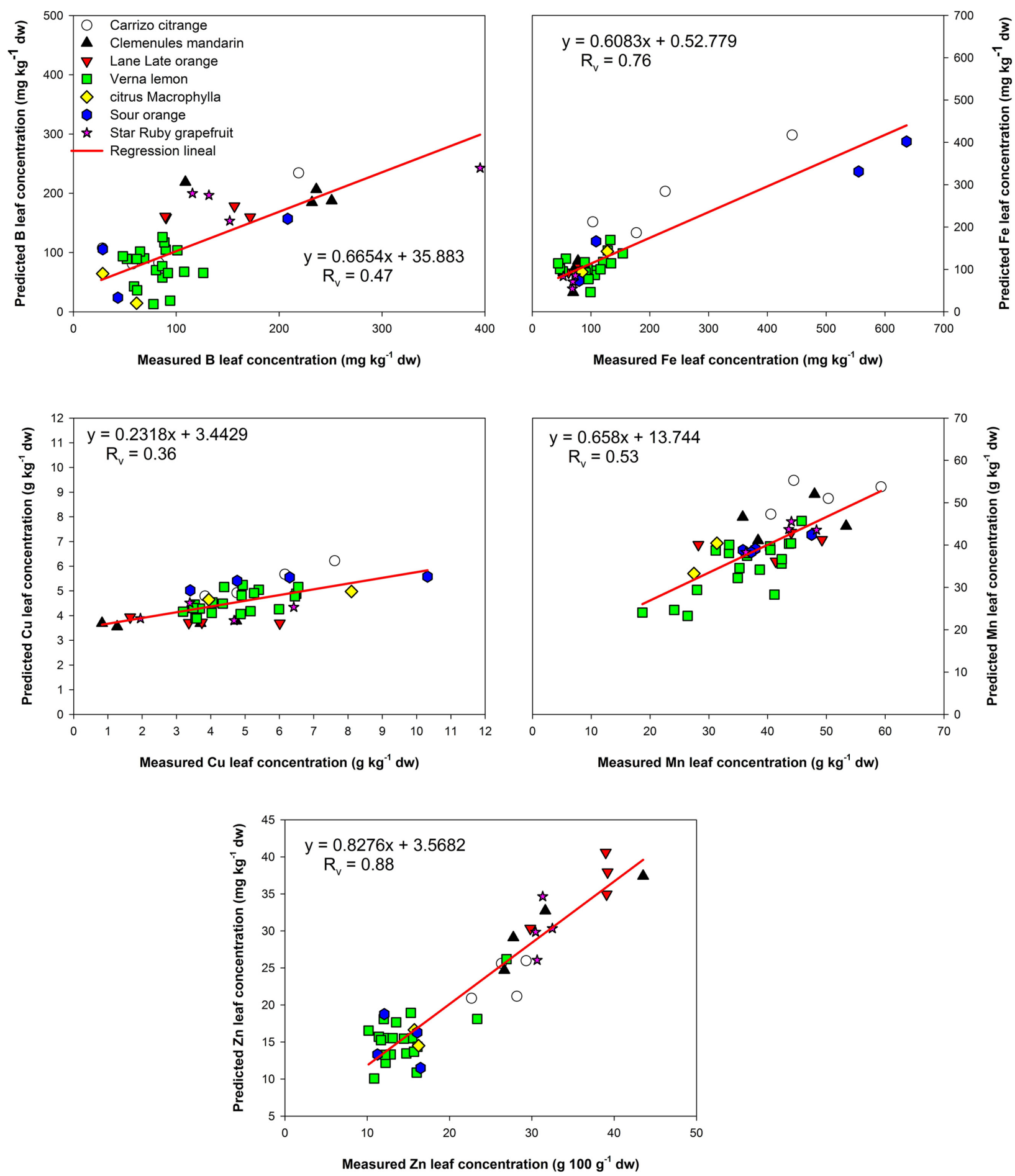

FIGURE 3 | Near infrared reflectance spectroscopy validation plots between predicted and real (measured) values for B, Fe, Cu, Mn, and $\mathrm{Zn}$.

\section{Conclusion}

The results showed that NIRS can constitute a feasible technique to quantify several macro and micronutrients such as, $\mathrm{N}, \mathrm{K}, \mathrm{Ca}, \mathrm{Mg}, \mathrm{Fe}$, and $\mathrm{Zn}$ in citrus leaves of different species. Therefore, NIRS would be a promising alternative to acquire a predictive view of the nutrient concentration of citrus leaves, thereby, facilitating the evaluation of the plant nutritional status of the trees. This technique provides a very interesting opportunity for future monitoring experiments, 
providing reliable results that can be obtained quickly, easily, and at low economic cost.

\section{Author Contributions}

MN developed the research hypothesis and the study design. JPP, VG, JN performed field sampling and chemical analysis. LG-S, FG-S performed NIR scanning, calibration model development.

\section{References}

Alomar, D., Fuchslocher, R., and de Pablo, M. (2003). Effect of preparation on composition and NIR spectra of forage samples. Anim. Feed Sci. Technol. 107, 191-200. doi: 10.1016/S0377-8401(03)00124-X

Baldock, J., and Schulte, E. (1996). Plant analysis with standardized scores combines DRIS and sufficiency range approaches for corn. Agron. J. 88, 448-456. doi: 10.2134/agronj1996.000219620088000 30015x

Beaufils, E. R. (1973). Diagnosis and recommendation integrated system (DRIS). A general scheme for experimentation and calibration based on principles developed from research in plant nutrition. Soil Sci. 1, 1-132.

Cayuela, J. A. (2008). Vis/NIRS soluble solids prediction in intact oranges (Citrus sinensis L.) cv. Valencia Late by reflectance. Postharvest Biol. Technol. 47, 75-80. doi: 10.1016/j.postharvbio.2007.06.005

Cerdá, A., Nieves, M., and Martínez, V. (1995). An evaluation of mineral analysis of 'Verna'lemons by DRIS. Commun. Soil Sci. Plant Anal. 26, 1697-1707. doi: 10.1080/00103629509369402

Galvez-Sola, L., Moral, R., Perez-Murcia, M. D., Perez-Espinosa, A., Bustamante, M. A., Martinez-Sabater, E., et al. (2010). The potential of near infrared reflectance spectroscopy (NIRS) for the estimation of agroindustrial compost quality. Sci. Total Environ. 408, 1414-1421. doi: 10.1016/j.scitotenv.2009.11.043

Galvez-Sola, L., Morales, J., Mayoral, A. M., Paredes, C., Bustamante, M. A., Marhuenda-Egea, F. C., et al. (2013). Estimation of parameters in sewage sludge by near-infrared reflectance spectroscopy (NIRS) using several regression tools. Talanta 110, 81-88. doi: 10.1016/j.talanta.2013. 02.009

García-Martínez, S., Gálvez-Sola, L. N., Alonso, A., Agulló, E., Rubio, F., Ruiz, J. J., et al. (2012). Quality assessment of tomato landraces and virus-resistant breeding lines: quick estimation by near infrared reflectance spectroscopy. J. Sci. Food Agric. 92, 1178-1185. doi: 10.1002/jsfa.4661

Gislum, R., Micklander, E., and Nielsen, J. P. (2004). Quantification of nitrogen concentration in perennial ryegrass and red fescue using near-infrared reflectance spectroscopy (NIRS) and chemometrics. Field Crop Res. 88, 269277. doi: 10.1016/j.fcr.2004.01.021

Halgerson, J. L., Sheaffer, C. C., Martin, N. P., Peterson, P. R., and Weston, S. J. (2004). Near-infrared reflectance spectroscopy prediction of leaf and mineral concentrations in alfalfa. Agron. J. 96, 344-351. doi: 10.2134/agronj2004.0344

He, Y., Min, H., García, A., Hernández, A., and Song, H. (2007). Prediction of soil macronutrients content using near-infrared spectroscopy. Comput. Electron. Agric. 58, 144-153. doi: 10.1016/j.compag.2007.03.011

Hernández Gómez, A., He, Y., and García Pereira, A. (2006). Non-destructive measurement of acidity, soluble solids and firmness of Satsuma mandarin using Vis/NIR-spectroscopy techniques. J. Food Eng. 77, 313-319. doi: 10.1016/j.jfoodeng.2005.06.036
$\mathrm{RM}, \mathrm{JM}-\mathrm{N}$ performed statistical analysis. The final manuscript is the end product of joint writing efforts of all authors.

\section{Acknowledgment}

Funding for this research came from the Ministry of Education and Science, government of Spain (Project Plan National AGL2011-24795).

Huang, G., Han, L., Yang, Z., and Wang, X. (2008). Evaluation of the nutrient metal content in Chinese animal manure compost using near infrared spectroscopy (NIRS). Bioresour. Technol. 99, 8164-8169. doi: 10.1016/j.biortech.2008.03.025

Jones, J., Wolf, B., and Mills, H. (1991). Plant Analysis Handbook. Athens, GA: Micro-Macro Publishing.

Kelling, K. A., and Schulte, E. E. (1986). DRIS as a part of routine plant analysis program. J. Fertilizer Issues 3, 107-112.

Ludwig, B., and Khanna, P. K. (2001). "Use of near infrared spectroscopy to determine inorganic and organic carbon fractions in soil and litter," in Assessment Methods for Soil Carbon, eds R. Lal, J. M. Kimble, R. F. Follett, and B. A. Stewart (Boca Raton: CRC/Lewis Publishers), 361-370.

Malley, D. F., Ben-Dor, E., and Martin, P. D. (2004). "Application in analysis of soils," in Near Infrared Spectroscopy in Agriculture, eds C. Robert, J. Workman, and J. B. Reeves (Madison: American Society of Agronomy, Soil Science Society of America and Crop Science Society of America), 729-784.

Menesatti, P., Antonucci, F., Pallotino, F., Roccuzzo, G., Allegra, M., Stagno, F., et al. (2010). Estimation of plant nutritional status by Vis-NIR spectrophotometric analysis on orange leaves [Citrus sinensis (L) OsbeckcvTarocco]. Biosyst. Eng. 105, 448-454. doi: 10.1016/j.biosystemseng.2010.01.003

Min, M., Lee, W. S., Burks, T. F., Jordan, J. D., Schumann, A. W., Schueller, J. K., et al. (2008). Design of a hyperspectral nitrogen sensing system for orange leaves. Comput. Electron. Agric. 63, 215-226. doi: 10.1016/j.compag.2008.03.004

Steuer, B., Schulz, H., and Läger, E. (2001). Classification and analysis of citrus oils by NIR spectroscopy. Food Chem. 72, 113-117. doi: 10.1016/S03088146(00)00209-0

Walsh, L. M. (1973). Soil and Applied Nitrogen. Soil and Applied Phosphorus. Soil and Applied Potassium. Soil and Applied Boron. Soil and Applied Calcium. Soil and Applied Magnesium. University of Wisconsin Extension Bulletin A2519 to A2524. Madison, WI: University Wisconsin Extension.

Zude, M., Pflanz, M., Kaprielian, C., and Aivazian, B. L. (2008). NIRS as a tool for horticulture in the citrus industry. Biosyst. Eng. 99, 455-459. doi: 10.1016/j.biosystemseng.2007.10.016

Conflict of Interest Statement: The authors declare that the research was conducted in the absence of any commercial or financial relationships that could be construed as a potential conflict of interest.

Copyright (C) 2015 Galvez-Sola, García-Sánchez, Pérez-Pérez, Gimeno, Navarro, Moral, Martínez-Nicolás and Nieves. This is an open-access article distributed under the terms of the Creative Commons Attribution License (CC BY). The use, distribution or reproduction in other forums is permitted, provided the original author(s) or licensor are credited and that the original publication in this journal is cited, in accordance with accepted academic practice. No use, distribution or reproduction is permitted which does not comply with these terms. 